\title{
KEMAMPUAN BAHAN AKTIF EKSTRAK AEGLE MARMELOS DALAM PENGENDALIAN DENGUE HEMORRHAGIC FEVER
}

\author{
Damar Prayogo ${ }^{1}$, Dumilah Astuti ${ }^{1}$ \\ ${ }^{1}$ Universitas Airlangga, Jl. Mulyosari Surabaya, Indonesia
}

\begin{abstract}
Dengue Hemorrhagic Fever (DHF) is a disease transmitted by the Aedes aegypti mosquito. The use of insecticides derived from the mojo plant (Aegle marmelos L.) contains tannins, saponins, alkaloids, flavonoids, terpenoids, and steroids, which function as larvicides. This study aims to determine the ability of mojo leaf extract (Aegle marmelos L.) in controlling the Aedes aegypti mosquito with the electric method using 2 concentrations, namely $60 \%$ and $70 \%$. Based on the results of the study, it was found that the average mosquito mortality at a concentration of $60 \%$ of mojo leaf extract (Aegle marmelos L.) was 16\%, from 30 samples of mosquitoes, at 240 minutes of observation time, and $70 \%$ concentration of mojo leaf extract (Aegle marmelos L. ) by 18\%, from 30 samples of mosquitoes, at 240 minutes of observation time. According to the Lethal Concentration $50\left(L C_{50}\right)$ where the average number of dead Aedes aegypti mosquitoes reached $16(53 \%)$ and $18(56 \%)$, while in the control there were no dead mosquitoes. The conclusion obtained in this study is that at concentrations of $60 \%$ and $70 \%$ of mojo leaf extract (Aegle marmelos L.) it is capable of 240 minutes with 240 minutes of observation time, where the average mortality of Aedes aegypti mosquitoes is 16 (53\%) and 17 tails $(56 \%)$ and have reached $L C_{50}$.
\end{abstract}

Keywords: Mojo Leaf, Aedes aegypti, Electric Method.

\begin{abstract}
ABSTRAK
Penyakit Demam Berdarah Dengue (DBD) merupakan penyakit yang ditularkan oleh nyamuk Aedes aegypti. Penggunaan insektisida yang berasal dari tumbuhan mojo (Aegle marmelos L.) mengandung senyawa tanin, saponin, alkaloid, flavonoid, terpenoid, dan steroid, yang berfungsi sebagai larvasida. Penelitian ini bertujuan untuk mengetahui kemampuan ekstrak daun mojo (Aegle marmelos L.) dalam mengendalikan nyamuk Aedes aegypti dengan metode elektrik dengan menggunakan 2 konsentrasi yaitu $60 \%$ dan $70 \%$. Berdasarkan hasil penelitian diketahui kematian nyamuk rata-rata pada konsentrasi 60\% ekstrak daun mojo (Aegle marmelos L.) sebesar 16\%, dari 30 ekor sampel nyamuk, pada 240 menit waktu pengamatan, dan konsentrasi $70 \%$ ekstrak daun mojo (Aegle marmelos L.) sebesar $18 \%$, dari 30 ekor sampel nyamuk, pada 240 menit waktu pengamatan. Memenuhi Lethal Consentration 50 ( $\left(\mathrm{LC}_{50}\right)$ dimana nyamuk Aedes aegypti yang mati rata-rata mencapai 16 ekor (53\%) dan 18 ekor (56\%), sedangkan pada kontrol tidak terdapat nyamuk yang mati. Kesimpulan yang di peroleh dalam penelitian ini yaitu Pada konsetrasi $60 \%$ dan $70 \%$ ekstrak daun mojo (Aegle marmelos L.) mampu pada 240 menit dengan 240 menit waktu pengamatan, dimana rata-rata kematian nyamuk Aedes aegypti sebanyak 16 ekor (53\%) dan 17 ekor (56\%) dan telah mencapai LC $\mathrm{C}_{50}$.
\end{abstract}

Kata Kunci: Daun Mojo, Aedes aegypti, Metode Elektrik. 


\section{INTRODUCTION}

Vektor adalah serangga atau binatang yang dapat membawa bibit penyakit dan menularkan kepada orang lain sehingga orang tersebut akan menjadi sakit. Penyakit Demam Berdarah Dengue (DBD) adalah salah satu masalah kesehatan masyarakat di Indonesia terutama untuk daerah perkotaan karena lebih banyak menyerang anak-anak dan dapat menular dalam waktu yang relatife singkat (Genis Ginanjar, 2004).

DBD (Demam Berdarah Dengue) adalah penyakit yang disebabkan oleh virus dengue. Penderita demam berdarah akan ditandai dengan gejala klinis berupa demam tinggi yang berlangsung terus menerus selama 2-7 hari, pendarahan yang biasanya didahului tanda khas berupa bintik-bintik merah (petechia) pada penderita, hepatomegali dan kegagalan peredaran darah.Vektor utama dari demam berdarah adalah nyamuk Aedes aegypti dan Aedes albopictus se bagai vektor potensial (Hoedojo dkk, 1998). Penyakit DBD pertama kali ditemukan pada tahun 1968 di Surabaya dengan kasus 58 orang anak, 24 diantaranya meninggal dengan Case Fatality Rate $(\mathrm{CFR})=41,3 \%$.

Salah satu upaya pemutusan rantai penularan penyakit dilakukan dengan pengendalian terhadap stadium larva melalui abatesasi dengan menggunakan arganofosfat temefos dan foging terhadap nyamuk dewasa dengan menggunakan malation. Pemberantasan dengan menggunakan insektisida kimiawi sampai sekarang masih digunakan meskipun resiko terhadap pencemaran lingkungan dan resistensi serangga sendiri terhadap insektisida sudah banyak terjadi. WHO (1998) menganjurkan pengendalian vektor dilakukan secara hayati yang lebih ramah lingkungan. Salah satu pengendalian hayati yaitu penggunaan insektisida nabati.

Salah satu tanaman yang mudah di dapat dan bermanfaat bagi manusia adalah tanaman mojo (Aegle marmelos L). Buah Mojo yang matang dapat dimakan langsung atau dibuat serbat, sirup dan nektar buah. Buah yang matang dapat di iris- iris, dikeringkan dan digunakan sebagai obat disentri kronis, diare, dan sembelit kulit buah mentah dapat digunakan sebagai cat kuning dan sebagai agen tanin. Kulit batang ini digunakan untuk meracuni ikan. Akar Mojo digunakan sebagai obat penenang debaran jantung, gangguan pencernaan, dan bengkak lambung. Daun, akar, dan kulit batang Mojo (Aegle marmelos L.) mengandung saponin, di samping itu akar dan kulit batangnya mengandung flavonoid dan polifenol dan daunnya juga mengandung tanin (Depkes RI, 1991).

Berdasarkan hasil uji pendahuluan yang dilakukan di laboratorium rekayasa Universitas Airlangga yang mengunakan ekstrak daging buah mojo (Aegle marmelos L.) dengan konsentrasi $50 \%$ dan $65 \%$ yang di dipaparkan pada 20 ekor nyamuk Aedes aegypti yang di 
dapatkan hasil kematian nyamuk Aedes aegypti mencapai 20 ekor dalam waktu 45 menit dengan konsentrasi $50 \%$ dan 30 menit pada konsentrasi 65\%. Berdasarkan latar belakang di atas penulis tertarik untuk melakukan penelitian dengan Judul : "Ekstrak Daging Buah Mojo (Aegle Marmelos L.) dalam mengendalikan nyamuk Aedes aegypti dengan Metode Elektrik”.

\section{METHOD}

Penelitian ini bersifat eksperimen dengan melakukan uji coba ekstrak buah mojo dalam mematikan nyamuk Aedes aegypti. Hal ini bertujuan untuk mengetahui kemampuan ekstrak daging buah mojo dalam mematikan nyamuk Aedes aegypti. Penelitian ini dilaksanakan di Laboratorium Rekayasa Universitas Airlangga. Waktu penelitian ini dilaksanakan mulai pada Juli sampai Oktober 2019 dan dibagi menjadi 2 (dua) tahapan, yaitu:

Tahap Persiapan, meliputi pengumpulan data-data baik itu data primer maupun data sekunder dalam penyusunan proposal yang dilakukan pada bulan Juli sampai dengan bulan September 2019. Tahap Pelaksanaan merupakan tahap pengamatan yang dilakukan di laboratorium pada saat penelitian terhadap jentik nyamuk Aedes aegypti yang dilaksanakan pada bulan Agustus sampai dengan Oktober 2018. Variabel bebas: konsentrasi daging buah mojo 50\%, 65\% yang dapat mempengaruhi variabel terikat yaitu kematian Aedes aegypti.

Variabel terikat: konsentrasi buah mojo 50\%, 65\% Variabel pengganggu: yaitu suhu dan lama ketahanan ekstrak (expire). Ekstrak daging buah mojo dalam penelitian ini adalah cairan yang berasal dari proses ekstraksi daging buah mojo yang diukur dengan volimetri yang menggunakan satuan ukur mili liter (ml). Konsentrasi ekstrak daging buah mojo dalam penelitian ini adalah sejumlah konsentrasi ekstrak daging buah mojo yang diukur dengan satuan persen (\%).

Nyamuk Aedes aegypti yang terusir dalam penelitian ini adalah hasil pengamatan pada saat melakukan pengujian atau pemaparan antara nyamuk Aedes aegypti dengan ekstrak daging buah mojo yang diukur dengan jumlah nyamuk yang mati dari alat anti nyamuk yang dipasang ditengah kurungan. Suhu dalam penelitian ini adalah tempertaur udara pada ruangan yang diukur dengan alat thermometer dengan satuan ukur ${ }^{\circ} \mathrm{C}$. Ketahanan ekstrak (expire) dalam penelitian ini adalah lamanya waktu tinggal ekstrak agar dapat digunakan kembali, waktu yang digunakan yaitu 1 minggu. Pengujian anti nyamuk elektrik dengan ekstrak daging buah mojo dinyatakan mampu dan efektif dalam mengusir nyamuk apabila pada saat diujikan dengan 20 ekor nyamuk Aedes aegypti yang berada didalam kurungan, nyamuk yang terusir mencapai 50\%. Dikatakan tidak mampu dan tidak efektif mengusir nyamuk apabila pada saat 
diujikan dengan 20 ekor nyamuk Aedes aegypti yang berada didalam kurungan, nyamuk yang terusir tidak mencapai 50\%. Data primer adalah data yang diperoleh berdasarkan hasil uji pendahuluan yang telah dilakukan. Hal ini dilakukan untuk memastikan apakah ekstrak daging buah mojo yang dibuat mampu mengendalikan nyamuk Aedes aegypti.

Data sekunder adalah data yang diperoleh dari berbagai referensi baik artikel-artikel, buku maupun literatur yang lain yang dianggap dapat mendukung teori yang ada, serta dianggap memiliki keterkaitan dengan penelitian ini.

\section{RESULTS AND DISCUSSION}

Hasil penelitian dengan menggunakan berbagai macam konsentrasi yaitu 50\% dan 65\%, ekstrak daging buah mojo (Aegle marmelos L.) yang dipaparkan pada nyamuk Aedes aegypti, selama empat jam dan diamati setiap 15 menit dimana setiap ruangan seluas 3 x 3 x 4 m, ( 36 $\mathrm{m}^{2}$ ), yang diisi 20 ekor nyamuk. Dan juga perlakuan kontrol yang berisi 20 ekor nyamuk Aedes aegypti.

Hasil pengamatan yang telah di lakukan pada kontrol dengan waktu pengamatan setiap 15 menit selama 240 menit yang diulang sebanyak Tiga kali, tidak terdapat nyamuk yang mati. Hal ini membuktikan bahwa kondisi lingkungan nyamuk yang terdapat dalam kamar tidak mempengaruhi kelangsungan hidup nyamuk tersebut. Pada kontrol tersebut tidak dipaparkan dengan konsentrasi ekstrak daging buah mojo (Aegle marmelos L.) namun diberikan perlakuan dengan memasukkan 20 ekor nyamuk Aedes aegypti kedalam ruangan.

Hasil pengamatan nyamuk Aedes aegypti yang mati setelah pemajanan dengan konsentrasi $50 \%$ ektrak daging buah mojo (Aegle marmelos L.).

Tabel 1. Hasil Pengamatan Nyamuk Aedes aegypti yang Mati setelah Pemajanan Dengan Konsentrasi 50\% Ektrak Daging buahMojo Setiap 15 Menit Pengamatan Selama 240 Menit

\begin{tabular}{|c|c|c|c|c|c|c|}
\hline \multirow{4}{*}{ No } & \multirow{4}{*}{$\begin{array}{c}\text { Waktu } \\
\text { Pengamatan }\end{array}$} & \multicolumn{3}{|c|}{ Jumlah Nyamuk Aedes aegypti yang Mati } & \multirow{3}{*}{ Kontrol } & \multirow{4}{*}{$\%$} \\
\hline & & \multicolumn{3}{|c|}{ Replikasi } & & \\
\hline & & $\mathbf{I}$ & II & III & & \\
\hline & & Mati & Mati & Mati & Mati & \\
\hline 1 & 15 Menit & 2 & 3 & 2 & - & 11,66 \\
\hline 2 & 30 Menit & 6 & 6 & 7 & - & 31,67 \\
\hline 3 & 45 Menit & 12 & 11 & 11 & - & 56,67 \\
\hline & Jumlah & 20 & 20 & 20 & - & 100 \\
\hline
\end{tabular}


Berdasarkan tabel 1 dapat dilihat bahwa pada konsentrasi $50 \%$ ekstrak daging buah mojo (Aegle marmelos L.) dengan waktu pengamatan selama 15 menit nyamuk Aedes aegypti yang mati pada relikasi I yaitu 2 ekor, replikasi II 3 ekor dan replikasi III 2 ekordalam ruangan, pengamatan 30 menit nyamuk yang mati pada replikasi I yaitu 6 ekor, replikasi II 6 ekor dan replikasi III 7 ekor pengamatan 45 menit nyamuk yang mati pada rep- likasi I sebanyak 12 ekor, replikasi II sebanyak 11 ekor, dan replikasi III sebanyak 11 ekor. Hasil pengamatan nyamuk Aedes aegypti yang mati setelah pemajanan dengan konsentrasi 65\% ektrak daging buah mojo (Aegle marmelos L).

Tabel 2. Hasil Pengamatan Nyamuk Aedes aegypti yang Mati Setelah Pemajanan Dengan Konsentrasi 65\% Ekstrak Daging buahMojo Setiap 15 Menit Pengamatan Selama 240 Menit

\begin{tabular}{|c|c|c|c|c|c|c|}
\hline \multirow{4}{*}{ No } & \multirow{4}{*}{$\begin{array}{c}\text { Waktu } \\
\text { Pengamatan }\end{array}$} & \multirow{2}{*}{\multicolumn{3}{|c|}{$\frac{\text { Jumlah Nyamuk Aedes aegypti yang Mati }}{\text { Replikasi }}$}} & \multirow{3}{*}{ Kontrol } & \multirow{4}{*}{$\%$} \\
\hline & & & & & & \\
\hline & & \multirow{2}{*}{$\frac{\text { I }}{\text { Mati }}$} & \multirow{2}{*}{$\frac{\text { II }}{\text { Mati }}$} & III & & \\
\hline & & & & Mati & Mati & \\
\hline 1 & 15 Menit & 7 & 7 & 8 & - & 36,67 \\
\hline 2 & 30 Menit & 13 & 13 & 12 & - & 63,33 \\
\hline \multicolumn{2}{|r|}{ Jumlah } & 20 & 20 & 20 & - & 100 \\
\hline
\end{tabular}

Berdasarkan tabel 2 dapat dilihat bahwa pada konsentrasi $65 \%$ ekstrak daging buah mojo (Aegle marmelos L.) dengan waktu pengamatan selama 15 nyamuk Aedes aegypti yang mati pada replikasi I yaitu 7 ekor, replikasi II 7 ekor, dan replikasi III 8 ekor, pengamatan 30 menit nyamuk yang mati pada replikasi I yaitu 13 ekor, replikasi II 13 ekor, dan replikasi III 12 ekor. Ekstrak daging buah mojo (Aegle marmelos L.) yang disimpan selama 1 minggu, dengan konsentrasi $50 \%$. 
Tabel 3. Hasil Pengamatan Nyamuk Aedes aegypti Yang Mati setelah Pemajanan Dengan Konsentrasi 50\% Ekstrak Daging buah Mojo yang telah disimpan selama 1 minggu. Setiap 15 Menit Pengamatan Selama 240 Menit

\begin{tabular}{ccccccc}
\hline & & \multicolumn{3}{c}{ Jumlah Nyamuk Aedes aegypti yang Mati } & \multirow{2}{*}{ Kontrol } & \multirow{2}{*}{ Replikasi } \\
\cline { 3 - 5 } No & Waktu & Pengamatan & I & II & III & \\
\cline { 3 - 6 } & & Mati & Mati & Mati & Mati & \\
\cline { 3 - 6 } & 15 Menit & 1 & 1 & 1 & - & 2,21 \\
\hline 1 & 30 Menit & 3 & 2 & 2 & - & 14,37 \\
3 & 45 Menit & 4 & 4 & 3 & - & 19,67 \\
4 & 60 Menit & 5 & 5 & 6 & - & 21,63 \\
5 & 75 Menit & 7 & 8 & 8 & - & 42,12 \\
\hline & Jumlah & 20 & 20 & 20 & - & 100 \\
\hline
\end{tabular}

Berdasarkan tabel 3 dapat dilihat bahwa pada konsentrasi 50\% ekstrak daging buah mojo (Aegle marmelos L.) yang telah disimpan selama 1 minggu dengan waktu pengamatan selama 15 menit nyamuk Aedes aegypti yang mati pada reli kasi I yaitu 1 ekor, replikasi II 1 ekor dan replikasi III 1 ekor dalam ruangan, pengamatan 30 menit nyamuk yang mati pada replikasi I yaitu 3 ekor, replikasi II 2 ekor dan replikasi III 2 ekor, pengamatan 45 menit nyamuk yang mati pada replikasi I sebanyak 4 ekor, replikasi II sebanyak 4 ekor, dan replikasi III sebanyak 3 ekor, pengamatan 60 menit nyamuk yang mati pada replikasi I sebanyak 5 ekor , replikasi II sebanyak 5 ekor, dan replikasi III sebanyak 6 ekor, pengamatan 75 menit nyamuk yang mati pada replikasi I sebanyak 7 ekor, replikasi II sebanyak 8 ekor, dan replikasi III sebanyak 8 ekor. Ekstrak daging buah mojo (Aegle marmelos L.) yang disimpan selama 1 minggu, dengan konsentrasi $65 \%$. 
Tabel 4. Hasil Pengamatan Nyamuk Aedes aegypti Yang Mati setelah Pemajanan Dengan Konsentrasi 65\% Ekstrak Daging buah Mojo yang telah disimpan selama 1 minggu. Setiap 15 Menit Pengamatan Selama 240 Menit

\begin{tabular}{|c|c|c|c|c|c|c|}
\hline \multirow{4}{*}{ No } & \multirow{4}{*}{$\begin{array}{c}\text { Waktu } \\
\text { Pengamatan }\end{array}$} & \multicolumn{3}{|c|}{ Jumlah Nyamuk Aedes aegypti yang Mati } & \multirow{3}{*}{ Kontrol } & \multirow{4}{*}{$\%$} \\
\hline & & \multicolumn{3}{|c|}{ Replikasi } & & \\
\hline & & $\mathbf{I}$ & II & III & & \\
\hline & & Mati & Mati & Mati & Mati & \\
\hline 1 & 15 Menit & 2 & 2 & 2 & - & 14,15 \\
\hline 2 & 30 Menit & 4 & 3 & 4 & - & 22,14 \\
\hline 3 & 45 Menit & 7 & 7 & 7 & - & 30,98 \\
\hline 4 & 60 Menit & 7 & 8 & 7 & - & 32,73 \\
\hline & Jumlah & 20 & 20 & 20 & - & 100 \\
\hline
\end{tabular}

Berdasarkan tabel 4 dapat dilihat bahwa pada konsentrasi $65 \%$ ekstrak daging buah mojo (Aegle marmelos L.) yang telah disimpan selama 1 minggu dengan waktu pengamatan selama 15 men- it nyamuk Aedes aegypti yang mati pada relikasi I yaitu 2 ekor, replikasi II 2 ekor dan replikasi III 2 ekor dalam ruangan, pengamatan 30 menit nyamuk yang mati pada replikasi I yaitu 4 ekor, replikasi II 3 ekor dan replikasi III 4 ekor, pengamatan 45 menit nyamuk yang mati pada replikasi I sebanyak 7 ekor, replikasi II sebanyak 7 ekor, dan replikasi III sebanyak 7 ekor, pengamatan 60 menit nyamuk yang mati pada replikasi I sebanyak 7 ekor , replikasi II sebanyak 8 ekor, dan replikasi III sebanyak 7 ekor.Ekstrak daging buah mojo (Aegle marmelos L.) yang disimpan selama 2 minggu, dengan konsentrasi $50 \%$.

Tabel 5. Hasil Pengamatan Nyamuk Aedes aegypti Yang Mati setelah Pemajanan Dengan Konsentrasi 50\% Ekstrak Daging buah Mojo yang telah disimpan selama 2 minggu. Setiap 15 Menit Pengamatan Selama 240 Menit

\begin{tabular}{|c|c|c|c|c|c|}
\hline \multirow{4}{*}{ No } & \multirow{4}{*}{$\begin{array}{c}\text { Waktu } \\
\text { Pengamatan }\end{array}$} & \multicolumn{3}{|c|}{ Jumlah Nyamuk Aedes aegypti yang Mati } & \multirow{3}{*}{ Kontrol } \\
\hline & & \multicolumn{3}{|c|}{ Replikasi } & \\
\hline & & $\mathbf{I}$ & II & III & \\
\hline & & Mati & Mati & Mati & Mati \\
\hline 1 & 15 Menit & 0 & 0 & 0 & - \\
\hline 2 & 30 Menit & 1 & 2 & 1 & - \\
\hline
\end{tabular}




\begin{tabular}{cccccc}
\hline & & \multicolumn{3}{c}{ Jumlah Nyamuk Aedes aegypti yang Mati } & \multirow{2}{*}{ Kontrol } \\
\cline { 3 - 5 } No & Waktu & \multicolumn{3}{c}{ Replikasi } & \\
\cline { 3 - 5 } & Pengamatan & I & II & III & Mati \\
\cline { 3 - 5 } & & Mati & Mati & Mati & - \\
\hline 3 & 45 Menit & 1 & 2 & 2 & - \\
4 & 60 Menit & 2 & 1 & 2 & - \\
5 & 75 Menit & 2 & 2 & 2 & - \\
6 & 90 Menit & 2 & 3 & 3 & - \\
7 & 105 Menit & 3 & 3 & 3 & - \\
8 & 120 Menit & 4 & 3 & 3 & - \\
9 & 135 Menit & 5 & 4 & 4 & 20 \\
\hline
\end{tabular}

Berdasarkan tabel 5 dapat dilihat bahwa pada konsentrasi $50 \%$ ekstrak daging buah mojo (Aegle marmelos L.) yang telah disimpan selama 2 minggu dengan waktu pengamatan selama 15 menit nyamuk Aedes aegypti yang mati pada replikasi I yaitu 0 ekor, replikasi II 0 ekor dan replikasi III 0 ekor dalam ruangan, pengamatan 30 menit nyamuk yang mati pada replikasi I yaitu 1 ekor, replikasi II 2 ekor dan replikasi III 1 ekor, pengamatan 45 menit nyamuk yang mati pada replikasi I sebanyak 1 ekor, replikasi II sebanyak 2 ekor, dan replikasi III sebanyak 2 ekor, pengamatan 60 menit nyamuk yang mati pada replikasi I sebanyak 2 ekor, replikasi II sebanyak 1 ekor, dan replikasi III sebanyak 2 ekor, pengamatan 75 menit nyamuk yang mati pada replikasi I sebanyak 2 ekor, replikasi II sebanyak 2 ekor, dan replikasi III sebanyak 2 ekor, pengamatan 90 menit nyamuk yang mati pada replikasi I sebanyak 2 ekor, replikasi II sebanyak 3 ekor, dan replikasi III sebanyak 3 ekor, pengamatan 105 menit nyamuk yang mati pada replikasi I sebanyak 3 ekor, replikasi II sebanyak 3 ekor, dan replikasi III sebanyak 3 ekor, pengamatan 120 menit nyamuk yang mati pada replikasi I sebanyak 4 ekor, replikasi II sebanyak 3 ekor, dan replikasi III sebanyak 3 ekor, pengamatan 135 menit nyamuk yang mati pada replikasi I sebanyak 5 ekor, replikasi II sebanyak 4 ekor, dan replikasi III sebanyak 4 ekor. Ekstrak daging buah mojo (Aegle marmelos L.) yang disimpan selama 2 minggu, dengan konsentrasi $65 \%$. 
Tabel 6. Hasil Pengamatan Nyamuk Aedes aegypti Yang Mati setelah Pemajanan Dengan Konsentrasi 65\% Ekstrak Daging buah Mojo yang telah disimpan selama 2 minggu. Setiap 15 Menit Pengamatan Selama 240 Menit

\begin{tabular}{cccccc}
\hline & & \multicolumn{3}{c}{ Jumlah Nyamuk Aedes aegypti yang Mati } & \multirow{2}{*}{ Kontrol } \\
\cline { 3 - 5 } No & Waktu & \multicolumn{3}{c}{ Replikasi } & \\
\cline { 3 - 5 } & Pengamatan & I & II & III & Mati \\
\cline { 3 - 5 } & & Mati & Mati & Mati & - \\
\hline 1 & 15 Menit & 1 & 1 & 1 & - \\
2 & 30 Menit & 2 & 2 & 3 & - \\
3 & 45 Menit & 3 & 3 & 3 & - \\
4 & 60 Menit & 3 & 3 & 3 & - \\
5 & 75 Menit & 3 & 3 & 3 & - \\
6 & 90 Menit & 4 & 4 & 3 & - \\
\hline 7 & 105 Menit & 4 & 4 & 4 & 20 \\
\hline
\end{tabular}

Berdasarkan tabel 6 dapat dilihat bahwa pada konsentrasi $65 \%$ ekstrak daging buah mojo (Aegle marmelos L.) yang telah disimpan selama 2 minggu dengan waktu pengamatan selama 15 menit nyamuk Aedes aegypti yang mati pada replikasi I yaitu 1 ekor, replikasi II 1 ekor dan replikasi III 1 ekor dalam ruangan, pengamatan 30 menit nyamuk yang mati pada replikasi I yaitu 2 ekor, replikasi II 2 ekor dan replikasi III 3 ekor, pengama- tan 45 menit nyamuk yang mati pada replikasi I sebanyak 3 ekor, replikasi II sebanyak 3 ekor, dan replikasi III sebanyak 3 ekor, pengamatan 60 menit nyamuk yang mati pada replikasi I sebanyak 3 ekor, replikasi II sebanyak 3 ekor, dan replikasi III sebanyak 3 ekor, pengamatan 75 menit nyamuk yang mati pada replikasi I sebanyak 3 ekor, replikasi II sebanyak 3 ekor, dan replikasi III sebanyak 3 ekor, pengamatan 90 menit nyamuk yang mati pada replikasi I sebanyak 4 ekor, replikasi II sebanyak 4 ekor, dan replikasi III sebanyak 3 ekor, pengamatan 105 menit nyamuk yang mati pada replikasi I sebanyak 4 ekor, replikasi II sebanyak 4 ekor, dan replikasi III sebanyak 4 ekor.

\section{Disscussion}

Hasil penelitian yang telah dilakukan dengan menggunakan dua macam kosentrasi yaitu, $50 \%$, dan $65 \%$ ekstrak daging buah mojo (Aegle marmelos L.) dengan perlakuan kontrol 
yang kemudian diulang sebanyak tiga kali selama 240 menit pengamatan dengan interval waktu setiap 15 menit, diperoleh jumlah nyamuk Aedes aegypti yang mati pada waktu pemaparan yang berbeda - beda dan konsentrasi yang berbeda pula serta lamanya penyimpanan estrak yang membuat kemampuan esktrak dalam mematikan nyamuk menurun. Pada kontrol terlihat bahwa tidak dijumpai adanya nyamuk Aedes aegypti yang mati. Hal ini membuktikan bahwa kondisi lingkungan nyamuk yang terdapat dalam kamar tidak mempengaruhi kelangsungan hidup nyamuk tersebut.

Kemampuan ekstrak daging buah mojo (Aeglemarmelos L.) dengan konsentrasi 50\% dalam mematikan nyamuk Aedes aegypti. Pada kosentrasi 50\% ekstrak daging buah mojo (Aegle marmelos L.) dengan pengamatan 15 menit pertama terdapat nyamuk Aedes aegypti yang mati pada replikasi I yaitu 2 ekor, replikasi II 3 ekor dan replikasi III 2 ekor dan sisanya masih aktif terbang menepi di pinggir kurungan, setelah 30 menit nyamuk yang mati pada replikasi I mencapai 8 ekor, replikasi II 9 ekor dan replikasi III 9 ekor, sedangkan sisanya hinggap di pinggir kurungan dan sudah mulai tidak aktif terbang, sedangakan pada 45 menit kemudian semua nyamuk sudah mati mencapai 20 ekor (100\%) pada replikasi pertama, kedua dan ketiga hasilnya tidak jauh berbeda. Setelah 240 menit pengamatan untuk memenuhi Lethal Consentration 50 ( $\left.\mathrm{LC}_{50}\right)$ dimana nyamuk yang mati mencapai 20 ekor (100\%) dengan tiga kali pengulangan.

Pada konsentrasi 50\% ini sudah dapat dikatakan efektif karena pada menit ke 45, kematian nyamuk Aedes aegypti $>50 \%$ pada replikasi I, II, dan III. Semakin lama nyamuk dikontakkan dengan ekstrak daging buah mojo maka kematian nyamuk juga akan semakin tinggi. Dengan konsentrasi ini, bahwa ekstrak daging buah mojo (Aegle marmelos L.) mampu membunuh nyamuk Aedes aegypti, dimana zat- zat yang terkandung dalam daging buah mojo (Aegle marmelos L.) dapat membunuh atau mengendalikan nyamuk. Dalam ekstrak daging buah mojo (Aegle marmelosL) ditemukan senyawa aktif golongan Alkaloid 7,12 \%, Terpenoid 4,4 \%, Tannin 14,12\%, Saponin 19,15\%, Flavonoid 6,13\% dan Steroid 3,11 \% yang berfungsi sebagai larvasida. Pada saponin masuknya zat toksik ini kedalam tubuh nyamuk adalah melalui saluran pencernaan. Pada saluran pencernaan zat toksik ini menurunkan aktivitas enzim pencernaan dan mengganggu proses penyerapan makanan sehingga saponin berfungsi sebagai racun perut dan tanin menpunyai bau yang sangat menyengat dan rasa yang pahit.zat toksik yang berperan untuk mematikan larva adalah, saponin, dan tannin. Berdasarkan hasil penelitian Nopianti (2008) menyebutkan bahwa saponin juga dapat digunakan sebagai insektisida. Kemampuan ekstrak daging buah mojo (Aegle marmelos L.) dengan konsentrasi 
65\% dalam mematikan nyamuk Aedes aegypti.

Pada kosentrasi 65\% ekstrak daging buah mojo (Aegle marmelos L.) dengan pengamatan 15 menit pertama terdapat nyamuk Aedes aegypti yang mati pada replikasi I yaitu 7 ekor, replikasi II 7 ekor dan replikasi III 8 ekor dan sisanya menepi di pinggir kurungan dan tidak aktif terbang, setelah 30 menit nyamuk yang mati pada replikasi I, II, III sudah mencapai 20 ekor nyamuk (100\%) setelah 120 menit pengamatan untuk memenuhi Lethal Consentration 50 ( $\left.\mathrm{LC}_{50}\right)$ dengan tiga kali pengulangan. Pada konsentrasi $65 \%$ ini sudah dapat dikatakan efektif karena pada menit ke 30, kematian nyamuk Aedes aegypti $>50 \%$ pada replikasi I, II, dan III. Semakin lama nyamuk dikontakkan dengan ekstrak daging buah mojo maka kematian nyamuk juga akan semakin tinggi.

Dengan konsentrasi ini, bahwa ekstrak daging buah mojo mampu membunuh nyamuk Aedes aegypti, dimana zat-zat yang terkandung dalam daging buah mojo (Aegle marmelos L.) dapat membunuh atau mengendalikan nyamuk Aedes aegypti pada kosentrasi 65\% ekstrak daging buah mojo, hal ini dikarenakan nyamuk menghirup aroma ekstrak daging buah mojo (Aegle marmelos L.) yang memiliki minyak atsiri yang mengandung zat - zat seperti, Alkaloid , Terpenoid, Tannin, Saponin , Flavonoid dan Steroid yang merupakan bahan aktif yang tidak disukai dan sangat dihindari serangga, termasuk nyamuk sehingga penggunaan bahan - bahan ini sangat bermanfaat sebagai bahan dalam mengendalikan nyamuk.

Zat-zat inilah yang memiliki sifat racun kontak yang aman apabila terhirup oleh manusia. Sebagai racun kontak dapat menyebabkan kematian akibat kehilangan cairan secara terusmenerus sehingga tubuh nyamuk kekurangan cairan dan akhirnya akan mati. Pada kosentrasi $50 \%$ ekstrak daging buah mojo (Aegle marmelos L.) yang telah disimpan selama 1 minggu dengan pengamatan 15 menit pertama terdapat nyamuk Aedes aegypti yang mati pada replikasi I yaitu 1 ekor, replikasi II 1 ekor dan replikasi III 1 ekor, setelah 30 menit nyamuk yang mati pada replikasi I 3 ekor, replikasi II 2 ekor dan replikasi III 2 ekor, setelah 45 menit kemudian nyamuk yang mati pada replikasi I 4 ekor, replikasi II 4 ekor dan replikasi III 3 ekor, pada 60 menit kemudian nyamuk yang mati pada replikasi I 5 ekor, replikasi II 5 ekor dan replikasi III 6 ekor, pada 75 menit kemudian nyamuk yang mati pada replikasi I 7 ekor, replikasi II 8 ekor dan replikasi III 8 ekor, pada menit ke 75 nyamuk sudah mati mencapai 20 ekor (100\%) pada replikasi pertama, kedua dan ketiga hasilnya tidak jauh berbeda. Setelah 240 menit pengamatan untuk memenuhi Lethal Consentration $50\left(\mathrm{LC}_{50}\right)$ dimana nyamuk yang mati mencapai 20 ekor $(100 \%)$ dengan tiga kali pengulangan.

Pada konsentrasi 50\% esktrak daging buah mojo yang disimpan selama 1 minggu ini 
sudah dapat dikatakan efektif karena pada menit ke 135, kematian nyamuk Aedes aegypti $>50 \%$ pada replikasi I, II, dan III. Meskipun menit kematian nyamuk bertambah dikarenakan ekstrak daging buah mojo telah disimpan selama 1 minggu sehingga kemampuan ekstrak semakin menurun pula.

Pada kosentrasi 65\% ekstrak daging buah mojo (Aegle marmelos L.) yang telah disimpan selama 1 minggu dengan pengamatan 15 menit pertama terdapat nyamuk Aedes aegypti yang mati pada replikasi I yaitu 2 ekor, replikasi II 2 ekor dan replikasi III 2 ekor, setelah 30 menit nyamuk yang mati pada replikasi I 4 ekor, replikasi II 3 ekor dan replikasi III 4 ekor, setelah 45 menit kemudian nyamuk yang mati pada replikasi I 7 ekor, replikasi II 7 ekor dan replikasi III 7 ekor, pada 60 menit kemudian nyamuk yang mati pada replikasi I 7 ekor, replikasi II 8 ekor dan replikasi III 7 ekor, pada menit ke 60 nyamuk sudah mati mencapai 20 ekor (100\%) pada replikasi pertama, kedua dan ketiga hasilnya tidak jauh berbeda. Setelah 240 menit pengamatan untuk memenuhi Lethal Consentration $50\left(\mathrm{LC}_{50}\right)$ dimana nyamuk yang mati mencapai 20 ekor (100\%) dengan tiga kali pengulangan.

Pada konsentrasi 65\% esktrak daging buah mojo yang disimpan selama 1 minggu ini sudah dapat dikatakan efektif karena pada menit ke 60, kematian nyamuk Aedes aegypti $>50 \%$ pada rep likasi I, II, dan III. Meskipun menit kematian nyamuk berbeda dengan ekstrak yang tidak disimpan sela- ma 1 minggu, sehingga kemampuan ekstrak semakin menurun pula.

Pada kosentrasi 50\% ekstrak daging buah mojo (Aegle marmelos L.) yang telah disimpan sela- ma 2 minggu dengan pengamatan 15 menit per- tama terdapat nyamuk Aedes aegypti yang mati pada replikasi I yaitu 0 ekor, replikasi II 0 ekor dan replikasi III 0 ekor, setelah 30 menit nyamuk yang mati pada replikasi I 1 ekor, replikasi II 2 ekor dan replikasi III 1 ekor, sedangakan pada 45 menit kemudian nyamuk yang mati pada replikasi I 1 ekor, replikasi II 2 ekor dan replikasi III 2 ekor, pada 60 menit kemudian nyamuk yang mati pada rep- likasi I 2 ekor, replikasi II 1 ekor dan replikasi III 2 ekor, pada 75 menit kemudian nyamuk yang mati pada replikasi I 2 ekor, replikasi II 2 ekor dan replikasi III 2 ekor, pada 90 menit kemudian nyamuk yang mati pada replikasi I 2 ekor, replikasi II 3 ekor dan replikasi III 3 ekor, pada 105 menit kemudian nyamuk yang mati pada replikasi I 3 ekor, replikasi II 3 ekor dan replikasi III 3 ekor, pada 120 menit kemudian nyamuk yang mati pada replikasi I 4 ekor, replikasi II 3 ekor dan replikasi III 3 ekor, pada 135 menit kemudian nyamuk yang mati pada replikasi I 5 ekor, replikasi II 4 ekor dan replikasi III 4 ekor, pada 13 menit nyamuk sudah mati mencapai 20 ekor (100\%) pada replikasi pertama, kedua dan ketiga hasilnya tidak jauh berbeda. Setelah 240 menit pengamatan untuk memenuhi Lethal Consentration $50\left(\mathrm{LC}_{50}\right)$ dimana nyamuk yang 
mati men- capai 20 ekor (100\%) dengan tiga kali pengulangan.

Pada konsentrasi 50\% esktrak daging buah mojo yang disimpan selama 2 minggu ini sudah dapat dikatakan efektif karena pada menit ke 135, kematian nyamuk Aedes aegypti $>50 \%$ pada replikasi I, II, dan III. Meskipun menit kematian nyamuk bertambah dikarenakan ekstrak daging buah mojo telah disimpan selama 2 minggu sehingga kemampuan ekstrak semakin menurun pula.

Pada kosentrasi 65\% ekstrak daging buah mojo (Aegle marmelos L.) yang telah disimpan selama 2 minggu dengan pengamatan 15 menit pertama terdapat nyamuk Aedes aegypti yang mati pada replikasi I yaitu 1 ekor, replikasi II 1 ekor dan replikasi III 1 ekor, setelah 30 menit nyamuk yang mati pada replikasi I 2 ekor, replikasi II 2 ekor dan replikasi III 3 ekor, sedangakan pada 45 menit kemudian nyamuk yang mati pada replikasi I 3 ekor, replikasi II 3 ekor dan replikasi III 3 ekor, pada 60 menit kemudian nyamuk yang mati pada replikasi I 3 ekor, replikasi II 3 ekor dan replikasi III 3 ekor, pada 75 menit kemudian nyamuk yang mati pada replikasi I 3 ekor, replikasi II 3 ekor dan replikasi III 3 ekor, pada 90 menit kemudian nyamuk yang mati pada replikasi I 4 ekor, replikasi II 4 ekor dan replikasi III 3 ekor, pada 105 menit kemudian nyamuk yang mati pada replikasi I 4 ekor, replikasi II 4 ekor dan replikasi III 4 ekor, pada 105 menit nyamuk sudah mati mencapai 20 ekor (100\%) pada replikasi pertama, kedua dan ketiga hasilnya tidak jauh berbeda. Setelah 240 menit pengamatan untuk memenuhi Lethal Consentration 50 (LC50) dimana nyamuk yang mati mencapai 20 ekor (100\%) dengan tiga kali pengulangan.

Pada konsentrasi $65 \%$ esktrak daging buah mojo yang disimpan selama 2 minggu ini sudah dapat dikatakan efektif karena pada menit ke 105, kematian nyamuk Aedes aegypti $>50 \%$ pada replikasi I, II, dan III. Meskipun menit kematian nyamuk bertambah dikarenakan ekstrak daging buah mojo telah disimpan selama 2 minggu sehingga kemampuan ekstrak semakin menurun pula. Dengan konsentrasi ini, bahwa ekstrak daging buah mojo (Aegle marmelos L.) mampu membunuh nyamuk Aedes aegypti, dimana zat- zat yang terkandung dalam daging buah mojo (Aegle marmelos L.) dapat membunuh atau mengendalikan nyamuk, meskipun waktu pemaparan nyamuk bertambah dikarenakan penyimpanan esktrak selama 1 minggu dan 2 minggu, yang menyembabkan kemampuan ekstrak menurun pula.

Hasil tersebut menunjukan bahwa pada kosentrasi 50\% dan 65\% ekstrak daging buah mojo (Aegle marmelos L.) serta ekstrak buah mojo yang telah disimpan selama 1 minggu dan 2 minggu, telah cukup mampu karena telah memenuhi standar LC 50 . Dimana Lethal Consentration 50 adalah kosentrasi tertentu suatu bahan yang mampu mematikan sebanyak 
$50 \%$ hewan percobaan, sehingga dapat dinyatakan bahwa waktu 240 menit pemaparan dengan kosentrasi 50\% dan 65\% ekstrak daging buah mojo (Aegle marmelos L.) adalah efektif dalam pengendalian nyamuk Aedes aegypti. (Sumirat Purwodo 1995)

Pada kontrol tidak ditemukan nyamuk yang mati, sehingga hasil yang diperoleh dapat mencerminkan hasil yang sebenarnya dan terdapat perbedaan antara perlakuan dengan jumlah kematian nyamuk pada masing-masing kosentrasi. Semakin tinggi kosentrasi perlakuan semakin banyak jumlah nyamuk Aedes aegypti yang mati.Hal ini disebabkan karena kandungan bahan kimia dalam ekstrak daging buah mojo (Aegle marmelos L.) yaitu minyak atsiri yang mengandung zat insektisida mempunyai dasar toksisitas yang juga tinggi. Sedangkan bila diperhatikan dari waktu lamanya pemajanan bahwa semakin lama waktu pemajanannya, jumlah nyamuk yang mati semakin banyak. Adanya perbedaan kematian nyamuk pada perlakuan I, II, dan III pada tabel 4.1, 4.2, 4.3, 4.4, 4.5, dan 4.6 bisa saja karena kekebalan tubuh nya- muk Aedes aegypti barbeda-beda, dan waktu penyimpanan ekstrak daging buah mojo selama 1 minggu dan 2 minggu, serta adanya pertukaran udara bebas dari luar ruangan yang mengakibatkan suhu ruangan dapat berganti-ganti di setiap perlakuan.

Hal ini sejalan dengan hasil penelitian ( Wahyuni S. 2005 ) Dengan melakukan pengujian ekstrak serai terhadap 25 ekor nyamuk Aedes aegypti dengan beberapa variasi konsetrasi dengan hasil konsentrasi yang terendah adalah $60 \%$ dapat membunuh nyamuk sebanyak 3,2\% dalam waktu 24 jam setelah perlakuan. Sedangkan konsentrasi yang tertinggi adalah $100 \%$ dalam waktu 24 jam setelah perlakuan dapat membunuh 17,6\% dari populasi nyamuk. Hal ini sudah dapat membunuh nyamuk lebih dari 10\%. Perilaku nyamuk Aedes aegypti adalah serangga yang aktif pagi hari dan siang menjelang sore hari, nyamuk akan mempunyai daya tahan tubuh yang lebih kebal terhadap pengaruh luar atau adanya perubahan kondisi dalam lingkungannya, dan pada saat terang nyamuk ini cenderung mengalami masa istirahat sehingga metabolisme tubuh atau daya tahan tubuh terhadap pengaruh dari lingkungan luar juga menurun.

Ekstrak daging buah mojo (Aegle marmelos L.) yang ditambahkan dengan 50\% dan 65\% aquadest sebagai pelarut untuk menghasilkan konsentrasi 50\%, dan 65\%, terbukti dapat mengusir dan mematikan nyamuk Aedes aegypti, dan konsentrasi paling efektif yaitu konsentrasi 60\% ekstrak daging buah mojo (Aegle marmelos L.) Sebagai anti nyamuk elektrik ekstrak daging buah mojo (Aegle marmelos L.) mempunyai mekanisme kerja yaitu berfungsi sebagai racun perut dan menpunyai bau yang sangat menyengat dan rasa yang pahit masuk kedalam tubuh nyamuk dalam bentuk partikel mikro atau uap melalui sistem pernafasan yang 
kemudian akan mempengaruhi syaraf pernafasan nyamuk sehingga akan mengalami kelabilan dan akhirnya mati. (Nopianti 2008).

Adapun hasil pengukuran suhu ruangan penelitian, yang diukur selama melakukan penelitian adalah sekitar $29^{\circ} \mathrm{C}$ sampai dengan $31^{\circ} \mathrm{C}$, suhu udara tersebut tidak mempengaruhi penelitian karena suhu yang terlalu tinggi atau terlalu rendah dapat mempengaruhi kelangsungan hidup nyamuk, dimana suhu minimum adalah $15^{\circ} \mathrm{C}$ dan suhu maksimum pada $45^{\circ}$ C. (Anonim e. 2011).

\section{CONCLUSION}

Dari hasil penelitian, dapat dilihat bahwa ekstrak daging buah mojo (Aegle marmelos L.) ternyata mampu dalam mengendaliakan nyamuk nyamuk Aedes aegypti. Pada konsetrasi $50 \%$ ekstrak daging buah mojo (Aegle marmelos L. ) mampu pada 45 menit dengan 240 menit waktu pengamatan, dimana kematian nyamuk Aedes aegypti $>50 \%$ dan telah mencapai LC $_{50}$,. Pada kosentrasi 65\% ekstrak daging buah mojo (Aegle marmelos L.) mampu pada 30 menit dengan 240 menit waktu pengamatan dimana kematian nyamuk Aedes aegypti $>50 \%$ dan telah mencapai LC $_{50}$. Pada konsetrasi $50 \%$ ekstrak daging buah mojo (Aegle marmelos L. ) yang telah disimpan selama 1 minggu mampu pada 75 menit dengan 240 menit waktu pengamatan, dimana kematian nyamuk Aedes aegypti $>50 \%$ dan telah mencapai LC $_{50}$, Pada kosentrasi 65\% ekstrak daging buah mojo (Aegle marmelos L.) yang telah disimpan seama 1 minggu mampu pada 60 menit dengan 240 menit waktu pengamatan dimana kematian nyamuk Aedes aegypti $>50 \%$ dan telah mencapai $\mathrm{LC}_{50}$. Pada konsetrasi $50 \%$ ekstrak daging buah mojo (Aegle marmelos $L$. ) yang telah disimpan selama 2 minggu mampu pada 135 menit dengan 240 menit waktu pengamatan, dimana kematian nyamuk Aedes aegypti $>50 \%$ dan telah mencapai $\mathrm{LC}_{50}$. Pada kosentrasi 65\% ekstrak daging buah mojo (Aegle marmelos L.) yang telah disimpan selama 2 minggu mampu pada 105 menit dengan 240 menit waktu pengamatan dimana kematian nyamuk Aedes aegypti $>50 \%$ dan telah mencapai $\mathrm{LC}_{50}$.

Hasil penelitian ini diharapkan dapat menjadi suatu alternatif pengendalian vektor khususnya terhadap nyamuk Aedes aegypti, ekstrak daging buah mojo (Aeglemarmelos L.) dapat difungsikan sebagai insektisida nabati karena aman bagi lingkungan dan manusia. Pada penelitian ini menggunakan ekstrak daging buah mojo (Aegle marmelos L.) diharapkan agar peneliti selanjutnya dapat mencoba ekstrak daging buah mojo (Aegle marmelos L.) muda dengan daging buah mojo (Aegle marmelos L.) sebagai pembanding. 


\section{ACKNOWLEDGMENTS}

Ucapan terimakasih kepada pihak-pihak terkait terutama pada Universitas Airlangga yang telah membantu dalam proses penelitian dan terima kasih khusus untuk semua data kolektor, pengawas, dan peserta studi.

\section{REFERENCES}

Ahmad Hamsir dkk. 2012. : Pengertian Vector Dan Binatang Pengganggu. Makassar :Poltekkes Makassar Jurusan Kesehatan Lingkungan.

Anonimb. 2012.Efektifitas Ekstrak Daun mojoi (aegle marmelos l) Untuk Mengendalikan jentik Aedes aegypti.

Ilyas, 2012.Kemampuan Ekstrak Daun Serai Sebagai Bahan Aktif Dalam Pengendalian Nyamuk CulexSp.Poltekkes Makassar Jurusan Kesehatan Lingkungan.

Khaer, Ain dan Sulasmi. 2010. Panduan Praktek Teknik Survey Pengendalian Vector Dan Binatang Pengganggu. Makassar :Poltekkes Makassar Jurusan Kesehatan Lingkungan.

Nurcahyati, Sri 2008 Efektivitas Ekstrak Daun Mojo (Aegle marmelos L.) Terhadap Kematian Larva Nyamuk Aedes aegypti Instar III., Universi- tas Muhammadiyah Surakarta.

Nopianti. 2008. Pengujian Beberapa Konsentrasi Ekstrak Buah Mojo pada jentik nyamuk eades aegyti. Jurusan Hama dan Penyakit berbasisi lingkingan, Universitas Hasanuddin.

Santi L. Yos, 2010, Efektifitas Ekstrak Kulit Durian ( Durio Zibethinus Murr)Sebagai Pengendali Nyamuk Aedes spp Tahun 2010, Fakultas Kesehatan Masyarakat Universitas Sumatera Utara

Sudiarianto .2010 Kasus Demam berdarah masih Endemik Di Indonesia Khususnya Wilayah Sulawesi Selatan .

Sumirat purwodo, 1995 Materi pengendalian hama supervisor perusahaan pengendalian hama. IPPHAMI jatim.

Wardani, S. 2009. Uji Aktivitas Minyak Atsiri Daun dan Batang Serai (Andropogon nardus L) sebagai Obat Nyamuk Elektrik terhadap Nyamuk Aedes aegypti. Skripsi Fakultas Farmasi Universitas Muhamadiyah Surakarta. 
WHO. 1999. DBD, Diagnosis, Pengobatan, Pencegahan, Dan Pengendalian. Penerbit buku kedokteran 